\title{
Sequências didáticas descritas por professores de matemática e de ciências naturais da rede pública: possíveis padrões e implicações na formação pedagógica de professores
}

\author{
Didactic sequences described by teachers of Mathematics \\ and Natural Sciences within a public school: possible patterns \\ and implications in the pedagogical formation of teachers
}

\author{
Maria Raquel Miotto Morelatti ${ }^{1}$. Paulo César de Almeida Raboni ${ }^{1}$ \\ - Leny Rodrigues Martins Teixeira ${ }^{2}$. Eliane Maria Vani Ortega ${ }^{1}$. \\ Monica Fürkotter ${ }^{1}$ • Edméa A. R. S. Raboni ${ }^{3}$. Regina Célia Ramos ${ }^{4}$
}

\begin{abstract}
Resumo: Este artigo tem como objetivo analisar sequências de atividades ou sequências didáticas descritas por professores de Matemática e da área de Ciências Naturais das escolas do Ensino Fundamental e Médio de Presidente Prudente (SP), na tentativa de identificar padrões implícitos nestas sequências, que possam revelar concepções de ensino destes professores. Ao analisarmos como 76 professores de Matemática e 61 de Ciências Naturais descrevem a sequência que utilizam em sala de aula, constatamos que a ação predominante é do professor nos três principais momentos da aula (início, desenvolvimento e avaliação). O professor inicia o conteúdo, estabelece a sequência, expõe, determina procedimentos, conclui e avalia, cabendo, ao aluno, a execução de atividades. Há uma diferença entre as sequências descritas nas duas áreas e algumas tentativas periféricas de superação do modelo tradicional de ensino. Essa questão é discutida tendo como foco os saberes da docência e a formação pedagógica do professor.
\end{abstract}

Palavras-chave: Sequência didática. Concepções de ensino. Formação de professores. Ensino de matemática. Ensino de ciências.

\begin{abstract}
This article aims to describe and analyze the possible didactic sequences practiced by Mathematics and Natural Sciences teachers at Elementary, Middle and High Schools of Presidente Prudente (SP), in order to identify implicit patterns in these sequences which may reveal the teaching conceptions of these teachers. When 76 Mathematics teachers and 61 Natural Sciences teachers were analyzed, we verified that the predominant action of the teacher is in three parts of the class (beginning, development and assessment). The teacher initiates the content, establishes a sequence, exposes and determines procedures, concludes and assesses it, and the students are supposed to execute the activities. There is a difference between the sequences described in both areas and some peripheral efforts trying to overcome the traditional model of teaching. This issue is discussed taking into consideration the teachers' knowledge about teaching and their pedagogical formation.
\end{abstract}

Keywords: Didactical sequence. Teaching conceptions. Teacher formation. Mathematics teaching. Natural sciences teaching.

\footnotetext{
${ }^{1}$ Programa de Pós-graduação em Educação, Faculdade de Ciências e Tecnologia, UNESP - Univ Estadual Paulista, Rua Roberto Simonsen, 305, Centro Educacional, CEP 190600-900, Presidente Prudente, SP, Brasil. E-mail: <mraquel@ffct.unesp.br>

${ }^{2}$ Programa de Pós-graduação em Educação, Universidade Católica Dom Bosco (UCDB), Campo Grande, MS, Brasil.

${ }^{3}$ Escola Estadual Fernando Costa, Presidente Prudente, SP, Brasil.

${ }^{4}$ Faculdade de Ciências e Tecnologia, UNESP - Univ Estadual Paulista, Presidente Prudente, SP, Brasil.
} 


\section{Introdução}

As mudanças que ocorreram no século XX marcaram profundamente a vida social, obrigando a educação, a escola e o professor a se repensarem, como forma de atender às novas demandas. Em consequência disso, a tarefa docente se tornou muito mais difícil. Além de alargar as perspectivas da ação educativa no sentido do desenvolvimento do ser humano plural, mais do que nunca é necessário assumir o desafio de ensinar, superando os modelos transmissivos e centralizadores.

Imbernón (2004) advoga que o professor não pode ser considerado um técnico, uma vez que se define pelo conhecimento pedagógico especializado legitimado pela ação. Trata-se de um conhecimento prático e, portanto, mais do que o domínio de uma disciplina ou de um conteúdo, assenta-se no modo pelo qual é construído, permitindo a inserção dos alunos em um mundo complexo, compreendido nas suas certezas e ambiguidades. Neste contexto, os professores, ao exercerem a atividade da docência, utilizam conhecimentos teóricos e práticos, sempre ressignificados a partir das demandas que surgem durante a ação da prática pedagógica.

Diante dessas considerações, Roldão (2007, p. 26) propõe que o saber profissional nuclear da docência é "saber ensinar como fazer aprender", levando-se em conta que esse saber "científico profissional global" apresenta variações conforme a área de conhecimento, o nível de escolaridade e o contexto da ação educativa, o que torna o saber profissional da docência bastante complexo.

Esta concepção sobre a docência encontra respaldo em outros autores com investigações nesse campo teórico. Tardif, Lessard e Lahaye (1991) caracterizam o saber da docência como heterogêneo, plural e temporal. Na verdade, tal saber é resultante de vários saberes: profissional (das ciências da educação e ideologia pedagógica), disciplinar, curricular e da experiência. Os saberes profissional, curricular e disciplinar se originam de conhecimentos, doutrinas e normas que embasam a ação pedagógica. Sendo externos, podem facultar ao professor ser apenas um agente de transmissão ou objeto dos saberes. Por sua vez, o saber da experiência resulta de escolhas, decisões e ações que envolvem intencionalidade e consciência, possibilitando a construção de saberes próprios, mediante a prática e a experiência. A prática docente é uma atividade complexa porque depende, em última instância, do conjunto dos saberes. Para compreendê-la, é necessário evidenciar como esses saberes se articulam, e não simplesmente identificá-los. $\mathrm{O}$ "saber" docente, no sentido amplo, constitui um amálgama entre as diferentes dimensões do saber, saber fazer e saber ser (TARDIF, 2000).

Shulman (1987) propõe que a especificidade do saber profissional para o ensino pode ser caracterizada pelo que denominou de conhecimento base da docência. Proposto como modelo de investigação, o conhecimento base sintetiza os saberes da docência, sendo marcado pela articulação entre o conteúdo, seu ensino e o currículo. Tal articulação supõe, portanto, vários tipos de saberes, conforme descrito a seguir: saber do conteúdo, envolvendo tanto as ideias essenciais de um campo (estrutura substantiva) quanto as formas e critérios de investigação do mesmo (estrutura sintática); saber de outros conteúdos mais gerais; saber pedagógico geral, relativo a aspectos mais amplos do processo de ensino e de aprendizagem; saber sobre o conteúdo pedagógico ou como deve ser o ensino de um item particular, o que supõe o saber sobre os alunos, como aprendem e se desenvolvem; saber curricular e suas diferentes formas de possibilitar o ensino dos conteúdos, e o saber sobre os objetivos educacionais e de ensino, colocados em ação, quando o 
conhecimento sobre o conteúdo se transforma em objeto de ensino. Em síntese, Shulman (1987) propõe que o conhecimento base da docência se apoia em um tripé caracterizado pelo conhecimento do conteúdo, a transformação desse conteúdo em objeto de ensino, ou seja, o conhecimento pedagógico do conteúdo, e o conhecimento curricular, que supõe a viabilização do ensino no currículo.

Apesar da importância do conhecimento base (SHULMAN, 1987) ou dos saberes (TARDIF, 2000), as pesquisas nesse campo teórico têm apontado que não é possível pensar a docência restrita à questão dos saberes, uma vez que o conhecimento pedagógico especializado do professor é bastante complexo e, como tal, requer uma formação densa que conjugue a preocupação com o desenvolvimento do conhecimento de base e das atitudes e valores de um profissional plural.

Em uma compilação das necessidades formativas apontadas pelas pesquisas, García (1999) identifica a concepção de que a formação de professores é um processo contínuo, que deve: integrar os conhecimentos pedagógicos e os disciplinares, a teoria e a prática, adequar a formação recebida ao tipo de educação que se pretende desenvolver, questionar as crenças e práticas vigentes, estar integrada aos processos organizacionais da escola, e deve integrar a formação e as propostas de mudança curricular e didática.

Referindo-se, também, à formação necessária ao profissional de ensino, Roldão (2007) aponta implicações que considera essenciais: a primeira, diz respeito à exigência de ter uma formação com qualidade científica, ou seja, o professor deve ser um "profissional da cultura" ou "de conhecimento", e não apenas um especialista de uma área; a segunda, refere-se à necessidade de se centrar a formação na ação de ensinar como um projeto articulado, e a terceira, destaca a necessidade de se dirigir a formação para a capacidade de conhecer e refletir para agir de forma fundamentada.

Em que pesem todas as investigações e avaliações a respeito da formação de professores, tem havido uma grande dificuldade em ultrapassar os desafios que os modelos de formação praticados têm imposto. No caso do nosso país, a maior parte dos cursos de formação inicial tem desenvolvido um currículo formal projetado por um tipo de racionalidade denominada técnica, porque é um modelo que estabelece uma relação linear entre conhecimento científico/técnico e suas aplicações, ou seja, baseia-se na ideia de que a teoria antecede a prática. Segundo PérezGoméz (1997, p. 107), é um modelo no qual "o mundo da investigação e o mundo da prática parecem formar círculos independentes, que rodam sobre si mesmos sem se encontrarem."

Esse modelo tem pouco contribuído para construir uma nova identidade do profissional docente, identidade essa de profissional reflexivo e investigador de suas próprias práticas e comprometido com a transformação social, como advoga Zeichner (1993).

Por outro lado, em relação à formação contínua, estudos e experiências têm mostrado que os cursos sob esse modelo têm se revelado pouco eficazes para promover a mudança da prática docente, uma vez que desconsideram o "saber experiencial dos professores, os quais não eram tomados como ponto de partida da formação continuada" (FIORENTINI; NACARATO, 2005, p. 8), não possibilitando a produção de novos saberes e práticas.

Para Fiorentini e Nacarato (2005), é necessário que a formação contínua aconteça dentro do espaço escolar, não como uma preocupação individual do professor, mas como um projeto da escola, que articule teoria e prática e seja integrado ao trabalho do professor. Nesta perspectiva, compreender a ação pedagógica docente supõe incidir o foco da análise sobre os 
saberes da experiência e seus fundamentos, constituídos num contexto de ensino, no qual múltiplos fatores se articulam, estabelecendo limites e controlando as possibilidades da sua atuação. É nesse contexto que o professor constrói seus esquemas de ação que, embora implícitos, são os responsáveis pelo seu fazer ou pela forma particular como estabelece sua rotina de trabalho e realiza improvisações frente à diversidade de problemas inerentes ao espaço pedagógico da sala de aula.

Sendo assim, é preciso descrever e analisar o cotidiano da sala de aula, no que diz respeito às decisões didáticas que o professor toma. Ensinar se concretiza por meio de uma sequência de atividades, as quais se baseiam em normas e códigos, consagrados pela experiência do professor ou pela tradição escolar. Para Zabala (1998, p. 20, grifo do autor),

[...] as sequências de atividades de ensino/aprendizagem, ou sequências didáticas, são uma maneira de encadear e articular as diferentes atividades ao longo de uma unidade didática. Assim, pois, poderemos analisar as diferentes formas de intervenção segundo as atividades que se realizam e, principalmente, pelo sentido que adquirem quanto a um sequência orientada para a realização de determinados objetivos educativos. As sequências podem indicar a função que tem cada uma das atividades na construção do conhecimento ou da aprendizagem de diferentes conteúdos e, portanto, avaliar a pertinência ou não de cada uma delas, a falta de outras ou a ênfase que devemos lhe atribuir.

Os tipos de atividades propostas, a maneira como elas se situam e se articulam, o papel que se atribui aos professores e alunos e à dinâmica grupal, e o tipo de relações que se estabelecem na aula diferenciam as propostas didáticas e determinam características diferenciais da prática educativa.

Neste artigo apresentamos resultados de uma investigação que teve por objetivo analisar sequências de atividades ou sequências didáticas descritas por professores das áreas de Matemática e de Ciências Naturais das escolas do Ensino Fundamental e Médio de Presidente Prudente (SP), na tentativa de identificar padrões implícitos nestas sequências, que possam revelar concepções de ensino destes professores.

Por se tratarem de áreas diferentes, Matemática e Ciências Naturais, em que a produção de conhecimento apresenta diferenças significativas quanto à relação com os objetos de conhecimento, implicando, mesmo, em objetos de naturezas diferentes, preconizam-se formas diferentes de ensinar. Em outras palavras, produzir conhecimentos na área de Matemática não é idêntico a produzir conhecimentos em Ciências Naturais, e essa diferença deve, ou deveria marcar igualmente padrões de ensino das disciplinas envolvidas.

Tal pesquisa foi desenvolvida no âmbito do Grupo de Pesquisa Ensino Aprendizagem como Objeto da Formação de Professores (GPEA) da Universidade Estadual Paulista Julio de Mesquita Filho (UNESP), campus de Presidente Prudente. 


\section{Metodologia}

Optamos por um estudo do tipo survey, por permitir analisar "uma amostra de uma determinada população, coletando dados sobre os indivíduos na amostra, para descrever e explicar a população que representam" (BABBIE, 1999, p. 107). Considerando o propósito da pesquisa, trata-se de um survey na vertente descritiva (PINSONNEAULT; KRAEMER, 1993), uma vez que buscamos identificar padrões que possam revelar concepções de ensino dos professores de Matemática e Ciências Naturais.

Os dados foram coletados por meio de um questionário, aplicado a 137 docentes, sendo 76 de Matemática e 61 da área de Ciências Naturais (Ciências no Ensino Fundamental; Física, Química e Biologia no Ensino Médio).

A tabulação dos dados foi realizada por meio da análise de conteúdo das respostas, seguida da definição de categorias. Trata-se de um procedimento de pesquisa em que, segundo Franco (2003), a expressão verbal, seus enunciados e suas mensagens, podem ser considerados indicadores indispensáveis para a compreensão dos problemas ligados às práticas educativas e seus componentes psicossociais. Para o tratamento dos dados, utilizamos o programa Statistical Package for the Social Sciences (SPSS) for Windows, que possibilitou a construção de tabelas com suas frequências e cruzamentos de dados.

Os dados aqui descritos e analisados referem-se a uma das questões do questionário, que solicitava a descrição da sequência didática utilizada pelo professor em sala de aula, a partir da escolha de um conteúdo ou tema. Nesta questão, os professores indicavam: como iniciavam a aula, quais os procedimentos a seguir, como concluíam a sequência, e como avaliavam a aprendizagem dos conceitos trabalhados.

\section{Descrição e análise dos dados}

A partir das sequências de atividades de ensino/aprendizagem descritas pelos professores de Matemática e da área de Ciências Naturais, tentamos identificar distintos padrões de ensino em cada uma das áreas e/ou eventualmente padrões comuns a elas.

As descrições dos três principais momentos da aula (início, desenvolvimento e avaliação da aprendizagem dos alunos) revelaram 23 tipos de atividades. A análise de conteúdo evidenciou quem está no centro da ação da atividade, gerando três categorias. A primeira, tendo o professor (P) como foco da atividade. A segunda, focando a atividade do aluno (A), e a terceira, referente a ambas, denominada compartilhada (C). A seguir, apresentamos as atividades de cada uma das três categorias:

- atividades realizadas pelo professor (P): exposição do conteúdo (leitura, texto na lousa etc.); exemplos/comparação/contextualização/ideia de multidisciplinaridade; execução de experimento/atividade prática (aula de campo); aplicação de provas escritas ou orais (avaliação dos conteúdos); avaliação de procedimentos e atitudes/avaliação contínua; correção de exercícios, problemas etc.; retomada de conceitos/conclusão (oral, texto, vídeo)/síntese.

- atividades compartilhadas porprofessor e aluno (C): o professor usa uma situação- problema (caso ou ideia a ser explorada pelo aluno); realização de experimento; uso de texto, vídeos e 
tabelas; aula dialogada (consideração ou não dos conhecimentos prévios dos alunos); discussão/ debate; uso de tecnologia; elaboração coletiva de conceitos.

- atividades realizadas pelos alunos (A): leitura simples (diferentes linguagens); pesquisas e levantamento de informações; trabalhos em grupo; resolução de exercícios de aplicação/resposta a questionários/trabalhos; interpretação/análise de diferentes textos (filme, tela, escultura, música, gráficos); produção de texto; atividade prática (dramatização/teatro/produção de vídeo/ jogos/oficinas/aulas de campo/atividades artísticas ou físicas); autocorreção/autoavaliação; seminário/exposição oral/exposição de trabalho realizado; relatórios/cartazes/exposição de trabalhos; reescrita de texto.

A seguir, analisamos como as atividades das três categorias estão presentes nos três momentos da aula, em Matemática e em Ciências Naturais. Cabe ressaltar que os professores indicaram uma única atividade para o início da aula, e mais de uma atividade para os dois momentos seguintes da aula, desenvolvimento e avaliação da aprendizagem dos alunos.

A Tabela 1 apresenta a distribuição de frequência das categorias no início da aula.

Tabela 1. Frequência de atividades das três categorias no início da aula

\begin{tabular}{lccccc}
\hline \multirow{2}{*}{ Categoria } & \multicolumn{5}{c}{ Início da aula } \\
\cline { 2 - 3 } & \multicolumn{2}{c}{ Matemática } & & Ciências Naturais \\
\cline { 2 - 3 } \cline { 5 - 6 } & Frequência & $\%$ & & Frequência & $\%$ \\
Professor (P) & 34 & 44,7 & & 26 & 42,6 \\
Compartilhada (C) & 27 & 35,5 & & 20 & 32,8 \\
Aluno (A) & 7 & 9,3 & & 11 & 18,0 \\
Em branco & 8 & 10,5 & & 4 & 6,5 \\
Total (N) & 76 & 100 & & 61 & 100 \\
\hline
\end{tabular}

$\mathrm{N}=$ número de sujeitos

Fonte: elaborado pelos autores a partir de dados da pesquisa.

Em Matemática, 44,7\% das atividades desenvolvidas no início da aula são centradas no professor, 35,5\% são compartilhadas entre professor e aluno, e apenas 9,3\% são desenvolvidas pelo aluno. Já em Ciências Naturais, a participação dos alunos é maior (18\%), sendo os percentuais de atividades realizadas pelo professor (42,6\%) ou compartilhadas (32,8\%) muito próximos aos de Matemática. Nos dois casos, há um percentual bastante significativo de atividades compartilhadas, o que aponta uma tentativa dos professores de envolverem os alunos no processo de ensino. Na realidade, os dados da tabela apontam a predominância de atividades centradas no professor ou compartilhadas $(80,2 \%)$ para Matemática $(80,2 \%)$ e para Ciências Naturais $(75,4 \%)$. Em consequência, podemos observar que o início da aula está marcado por um percentual pequeno centrado no aluno (9,3 em Matemática e 18\% em Ciências Naturais).

Em Matemática, a aula expositiva $(61,8 \%)$ e exemplos, comparações e contextualizações $(26,5 \%)$ foram os procedimentos mais frequentes quando o início da aula é centrado no professor, categoria (P). Outros procedimentos somam 11,7\%. Em Ciências Naturais, 70\% dos procedimentos descritos são de contextualização, e apenas $22 \%$ de aula expositiva, ambos pelo professor. Ao que parece, o professor de Ciências Naturais tem clareza da importância de 
contextualizar os temas abordados, enquanto o professor de Matemática prioriza a exposição formal do conteúdo.

Quando o início da aula de Matemática é compartilhado por professor e aluno, categoria (C), em geral, são utilizadas situações-problema exploradas pelo aluno $(55,6 \%)$ e aula dialogada (44,4\%), em que professores e alunos discutem, argumentam e opinam sobre o tema proposto. Nas aulas de Ciências Naturais, 33\% dos professores iniciam a aula dialogando com os alunos, e o procedimento predominante é o de exploração de situações ligadas ao cotidiano. Nesse início compartilhado, embora o professor permaneça no comando da atividade, os alunos são chamados a uma participação mais efetiva, por meio de diálogos, debates ou análise de situações-problema.

No caso em que o início das atividades está centrado no aluno, categoria (A), os procedimentos que apareceram com maior frequência foram: leitura de texto, pesquisas e atividade prática, todos com o mesmo percentual de 28,6\% para Matemática e de 18\% para Ciências Naturais.

Para descreverem o desenvolvimento de suas aulas, os professores mencionaram até três atividades diferentes que realizam com os alunos, totalizando 228 indicações possíveis em Matemática e 183, em Ciências Naturais.

$\mathrm{Na}$ Tabela 2 apresentamos a distribuição de frequência das categorias no desenvolvimento da aula.

Tabela 2. Frequência de atividades das três categorias no desenvolvimento da aula

\begin{tabular}{lccccc}
\hline \multirow{2}{*}{\multicolumn{1}{c}{ Categoria }} & \multicolumn{4}{c}{ Desenvolvimento da aula } \\
\cline { 2 - 3 } & \multicolumn{2}{c}{ Matemática } & & \multicolumn{2}{c}{ Ciências Naturais } \\
\cline { 2 - 3 } \cline { 5 - 6 } & Frequência & $\%$ & & Frequência & $\%$ \\
\hline Professor (P) & 69 & 30,3 & & 51 & 27,9 \\
Compartilhada (C) & 45 & 19,7 & & 25 & 13,7 \\
Aluno (A) & 13 & 5,7 & & 44 & 24,0 \\
Em branco & 101 & 44,3 & & 63 & 34,4 \\
Total (N) & 228 & 100 & & 183 & 100 \\
\hline
\end{tabular}

$\mathrm{N}=$ número de sujeitos

Fonte: elaborado pelos autores a partir de dados da pesquisa.

Ao analisarmos a Tabela 2, constatamos que, nas duas áreas, a maior frequência se refere à categoria em branco. No ensino de Matemática, a segunda maior frequência no desenvolvimento da aula está centrada na atividade do professor (30,3\%), em seguida, centrada no aluno $(19,7 \%)$ e compartilhada (5,7\%). Já em Ciências Naturais, há uma inversão entre o desenvolvimento de atividades pelos alunos $(24 \%)$ e as atividades compartilhadas (13,7\%). Para as duas áreas, o grande percentual das respostas em branco se deve, provavelmente, ao fato de que muitos dos professores centraram sua atenção na descrição do início da aula e de apenas alguns tipos de desenvolvimento.

Quando o desenvolvimento da aula de Matemática está centrado nas atividades do professor, categoria $(\mathrm{P})$, os procedimentos que mais aparecem são: exposição do conteúdo 
(49,3\%) e demonstração de exemplos/comparações (37,7\%). Como podemos observar, as atividades descritas no desenvolvimento apresentam a mesma tendência daquelas do início da aula, ou seja, nos dois casos os procedimentos adotados são do mesmo tipo. Em Ciências Naturais, o procedimento mais frequente para o desenvolvimento da aula também é exposição de conteúdos (42\%), enquanto leituras pelos alunos, realização de atividades práticas e resolução de exercícios comparecem em 31\% das descrições.

Para as duas áreas, no caso em que as atividades da aula estão centradas no aluno, categoria (A), mais de 70\% se restringem à resolução de exercícios e, quando a atividade é compartilhada, o procedimento de maior frequência refere-se a aulas dialogadas, em torno de $50 \%$.

Em relação à forma como avaliam os seus alunos, também organizamos os dados com base na quantidade de respostas, já que havia a possibilidade de os professores indicarem até dois procedimentos, obtendo 152 respostas possíveis para Matemática, e 122 para Ciências Naturais.

$\mathrm{Na}$ Tabela 3 apresentamos a distribuição de frequência das categorias no momento de avaliação da aprendizagem do aluno.

Tabela 3. Frequência de atividades das três categorias no momento de avaliação da aprendizagem do aluno

\begin{tabular}{lccccc}
\hline \multirow{2}{*}{ Categoria } & \multicolumn{4}{c}{ Desenvolvimento da aula } \\
\cline { 2 - 3 } & \multicolumn{2}{c}{ Matemática } & & \multicolumn{2}{c}{ Ciências Naturais } \\
\cline { 2 - 3 } \cline { 6 - 7 } & Frequência & $\%$ & & Frequência & $\%$ \\
\hline Professor (P) & 35 & 23 & & 14 & 11,5 \\
Compartilhada (C) & 5 & 3,3 & & 3 & 2,4 \\
Aluno (A) & 0 & 0 & & 6 & 4,9 \\
Em branco & 112 & 73,7 & & 99 & 81,2 \\
Total (N) & 152 & 100 & & 122 & 100 \\
\hline
\end{tabular}

$\mathrm{N}$ = número de sujeitos

Fonte: elaborado pelos autores a partir de dados da pesquisa

Cumpre destacar que a maioria dos professores não especifica quais são os procedimentos de avaliação, como pode ser conferido na Tabela 3 (73,7\% das respostas dos professores de Matemática e 81,2\%, dos professores de Ciências Naturais estão na categoria em branco). Entre os que responderam, há predominância de atividades avaliativas centradas no professor, categoria (P), tanto em Matemática (23\%) quanto em Ciências (11,5\%). Os procedimentos descritos nas atividades de avaliação centradas no professor são, na maioria, provas escritas (54,3\%), seguido da avaliação contínua (20,0\%), em Matemática, e, em Ciências Naturais, prova escrita $(8,2 \%)$ e resolução de exercícios $(2,5 \%)$.

Não há incidências de atividades de avaliação centradas nos alunos em Matemática, e apenas 4,9\% no caso de Ciências Naturais.

De modo geral, a análise das atividades que os professores descrevem sobre os procedimentos que realizam ao tratarem um conteúdo demonstra o predomínio de atividades centradas no professor em praticamente todos os momentos da aula. Foi possível constatar que a participação dos alunos restringe-se à execução de atividades determinadas pelo professor, tais como: leitura, pesquisa, coleta de material, resolução de exercícios e problemas. 
Para Thompson (1984), as práticas de ensino desenvolvidas pelos professores, em alguns casos, são direcionadas por noções e preferências inconscientes. Um exemplo de tal situação refere-se a resultados de pesquisa realizada pela autora em que uma professora, ao ser entrevistada, prioriza, em seu discurso, a participação dos alunos nas atividades realizadas nas aulas de Matemática, o que não se confirma quando se observa suas aulas.

A participação dos alunos era tipicamente limitada a responder as questões da professora, para as quais, na maioria das vezes, exigiam-se respostas curtas e simples, e ela tinha uma tendência a desconsiderar as sugestões dos alunos e não seguir com as idéias deles. (THOMPSON, 1984, p. 112, tradução nossa)

Ao que parece, ainda que o professor tenha clareza da importância da participação dos alunos nas atividades da aula, as ações dele obedecem a preferências inconscientes, muito provavelmente advindas dos percursos da sua experiência.

Outro autor que aponta a tendência de atividades na aula centradas no professor é Stephens (2003), ao descrever resultados de pesquisa em que analisa vídeos de classes de $8^{a}$ séries dos Estados Unidos da América e do Japão. Tal pesquisa demonstra que, no Japão, onde os resultados das avaliações em Matemática são melhores, os trabalhos colaborativos entre os alunos são obrigatórios. Já nos Estados Unidos, é possível delimitar uma tendência de atividades de ensino que segue os seguintes passos:

$1^{\circ} \mathrm{O}$ professor faz uma revisão do assunto tratado na aula anterior e das tarefas de casa. $2^{\circ} \mathrm{O}$ professor usa um problema para ilustração.

$3^{\circ} \mathrm{O}$ professor propõe exercícios fáceis que reproduzem o que foi demonstrado anteriormente.

$4^{\circ}$ Os alunos resolvem os exercícios, geralmente sozinhos, sob a supervisão do professor.

$5^{\circ} \mathrm{O}$ professor confere a resolução dos exercícios

$6^{\circ} \mathrm{O}$ professor propõe tarefa para casa.

Como fica evidente nos passos listados, as atividades são centradas no professor. Além disso, Stephens (2003) não encontrou provas matemáticas construídas pelos alunos nos vídeos analisados.

$\mathrm{Na}$ Inglaterra, também há estudos que mostram que as atividades realizadas em sala de aula são controladas, predominantemente, pelo professor, de acordo com Jaworski e Gellert (2003). O professor explica, demonstra e dá exemplos. Os alunos são orientados a seguir os passos para resolver questões fechadas sobre o que foi proposto previamente pelo professor. Estes autores entendem que os professores sentem dificuldades para propiciar maiores interações em sala de aula. Uma das razões apontadas para tais dificuldades refere-se ao receio de propor situações mais abertas, pois estas podem ter desdobramentos que fogem do controle do professor.

Como coloca Tardif (2010), a experiência como aluno certamente interfere na forma como são organizadas as sequências didáticas pelos professores. Um professor que, em sua vida escolar, não tenha vivenciado situações abertas, com a participação dos alunos, muito 
provavelmente prefira seguir um caminho considerado mais seguro para ele, interiorizado ao longo de sua vida escolar.

\section{Considerações finais}

Os eixos norteadores presentes nas propostas curriculares das áreas de Matemática e de Ciências Naturais afirmam a importância da atividade do aluno no processo de construção de conceitos. Nas reformas curriculares dos anos 1980/90, bem como no currículo do estado de São Paulo vigente a partir de 2008, um dos pontos em comum é a ênfase conferida à atividade do aluno, e a importância de se resgatar o estímulo de suas capacidades intuitivas e seus conhecimentos prévios. Por outro lado, nossas análises indicam um predomínio de sequências centradas no professor. Embora esta tendência se revele para os dois grupos de professores, há uma diferença entre as sequências descritas pelos professores de Matemática e os de Ciências Naturais. Em Matemática, há um padrão mais uniforme dessas sequências (aulas expositivas, seguidas de resolução de exercícios e avaliação por meio de prova escrita), enquanto, em Ciências Naturais, não é possível identificar um padrão, dada a diversidade de atividades e recursos pedagógicos presentes nos três momentos das aulas.

Sob esse aspecto, diferenças importantes entre Matemática e Ciências Naturais podem ser apontadas. No caso das Ciências, as relações estabelecidas pelos alunos com os objetos de conhecimento, que geram explicações de causalidade e promovem o contato com "variáveis" presentes nos fenômenos, são múltiplas. A todo momento, temos contato com o mundo físico, biológico e químico que favorece o desenvolvimento de explicações sobre os acontecimentos. Fenômenos envolvendo o calor e o frio, a luz e a escuridão, sombras, movimentos e forças, a vida e suas transformações, saúde e doença, mudanças de sabor e coloração nos alimentos, para citar apenas alguns exemplos, são parte do cotidiano de todas as pessoas, e as conduzem a explicações denominadas, pelas pesquisas em ensino de ciências, como: "cotidianas", "de senso comum", "concepções prévias", “concepções alternativas”, que abrangem um universo conceitual muito amplo quando comparado a outras disciplinas.

Como decorrência, seria de se esperar maior presença da "voz" dos alunos em aulas de Ciências Naturais. Em parte, ela ocorre, mas não com o sentido decorrente de diferenças epistemológicas entre as áreas. Respondem apenas pela maior disponibilidade de situações cotidianas envolvendo as Ciências, mas que se limitam a exemplos para ilustrar a explicação dada pelo professor, pelo livro ou pela ciência, e que exigem pouca ou nenhuma atividade intelectual dos alunos.

Nas duas áreas investigadas observamos, nas sequências didáticas, várias tentativas de superação do modelo tradicional de ensino, pautado na transmissão de conteúdos. Porém, essas tentativas são periféricas, por se limitarem à diversificação de atividades, que pouco desafiam intelectualmente os alunos. Em Matemática, os problemas se restringem a exercícios e, em Ciências Naturais, o cotidiano comparece apenas para ilustrar o conteúdo trabalhado. Esse modelo de ensino, que tem sido realizado há décadas, não necessariamente contempla procedimentos nos quais os alunos possam levantar hipóteses, conjecturar, fazer comparações e generalizações, como preconizam as atuais propostas pedagógicas. 
Os resultados do presente trabalho, ao que parece, confirmam a resistência às mudanças, tendo em vista o perfil dos sujeitos investigados. Dos 137 professores, mais de $60 \%$ possuem de 11 a 25 anos de magistério, o que significa uma parcela considerável de professores que, certamente, realizaram, em cursos de formação continuada, discussões sobre a importância da participação do aluno no processo de ensino e aprendizagem em Matemática e em Ciências Naturais. Ao menos no discurso, as descrições enfatizam a atividade do professor ao desenvolver um determinado conteúdo dessas disciplinas.

Para justificar a resistência às mudanças, além da tendência à própria estabilidade curricular destacada por Goodson (1997), a constituição dos saberes dos professores poderia justificar a predominância de um padrão de ensino centrado no professor. A questão que se coloca aqui é qual a razão da resistência à participação mais efetiva dos alunos. Qual o papel dos saberes constituídos pelos professores nesse processo?

Os saberes que os professores constituem ao longo de toda a sua escolaridade, bem como na formação inicial em curso de licenciatura, interferem na sua prática enquanto professores. Para Tardif (2000), os saberes profissionais dos professores não provêm somente da sua formação específica, mas, também, da sua própria história de vida, em particular, de sua história escolar.

Há pesquisas que demonstram que a prática do professor está diretamente ligada ao seu conhecimento e às suas crenças com relação à Matemática e ao seu ensino, que são fortemente influenciados por suas experiências prévias como estudantes de Matemática (POLETTINI, 1999). Por outro lado, as pesquisas também têm mostrado que é pouco visível a influência dos cursos de formação na prática docente. No geral, tanto para os professores de Matemática como para os de Ciências Naturais, a aprendizagem da docência se dá na prática, para a qual basta o conhecimento da matéria a ser ensinada (CARVALHO; GIL-PÉREZ, 1995; GARCÍA, 1999; GARCIA; PORLÁN, 2000).

Tendo em vista a ambiguidade que envolve a questão dos saberes, é importante compreender até que ponto os cursos de formação inicial podem alterar os saberes advindos da experiência prévia dos professores como alunos da Educação Básica.

A partir destas questões, entendemos que os formadores de professores têm a responsabilidade de organizar um trabalho capaz de não apenas possibilitar que os futuros professores dominem conceitos específicos das disciplinas, pedagógicos e curriculares, mas que tenham oportunidade de repensar e reconstruir os saberes adquiridos em sua trajetória escolar. Ações importantes nesse contexto são as próprias práticas pedagógicas dos formadores dos professores.

No geral, a prática vigente tanto nos cursos de formação inicial quanto nos de formação continuada tem contribuído para tal situação. Baseados no modelo da racionalidade técnica (PÉREZ GOMÉZ, 1997), no qual teoria e prática comparecem dissociadas, e na suposição de que a teoria se aplica automaticamente à prática, tal formato de curso acaba por reforçar a resistência à mudança. Mudar esse paradigma de formação, como aponta Schön (1992), supõe uma vinculação entre teoria e prática, a partir da prática. Para tanto, a formação deveria ter sua raiz nos problemas reais da escola e da sala de aula, a partir dos quais a fundamentação teórica seria solicitada como elemento essencial e imprescindível para análise e compreensão das vicissitudes da docência e serviria de base para superação dos problemas encontrados. 
Neste sentido, Pires (2000) alerta para a falta de coerência entre a formação pedagógica sugerida e o modelo de ensino de formação praticado nas licenciaturas. O predomínio de aulas expositivas e palestras, em detrimento de atividades de simulação de situações-problema e intercâmbio de experiências, é evidência dessa incoerência.

Em consequência, dada a precariedade da formação no sentido de instrumentalizar o professor para o ensino de Matemática e de Ciências Naturais em situação real, é comum que os professores reproduzam os padrões de ensino vivenciados.

Uma outra questão que emerge da análise dos dados refere-se às condições de trabalho dos professores. A maior parte dos investigados afirma possuir uma carga horária acima de 30 horas semanais. Esse professor tem tempo para estudar de forma contínua e sistemática e preparar aulas diferentes do que presenciou provavelmente em toda a sua vida escolar e, até mesmo, em disciplinas de conteúdos específicos no curso de licenciatura?

Esse aspecto, em especial, tem um agravamento no caso das disciplinas de Ciências Naturais, quando comparadas à Matemática, pois a carga horária é substancialmente menor para as Ciências. Isso faz com que os professores acumulem maior número de turmas e alunos, e atuem em mais de um nível de ensino. Como consequência, têm de preparar aulas com uma grande variedade de conteúdos, restando pouco tempo para a preparação das aulas e para o atendimento dos alunos.

Considerando as condições reais de trabalho dos professores nas escolas públicas, o padrão de ensino centrado no professor, com reduzida participação dos alunos, talvez seja, na visão dos professores, o padrão possível de ser praticado no modelo de escola que temos. É provável que a resistência desse padrão de ensino centrado no professor se deva ao seu caráter econômico, no sentido de que permite a ele não só ministrar muitas aulas apenas com um preparo básico, como, também, manter uma rotina de aula com base em uma mesma organização do tempo.

Levando-se em conta tudo o que tem sido recomendado e prescrito por pesquisas e propostas nos últimos anos, tendo em vista a superação do ensino tradicional, fica claro que qualquer uma dessas sugestões exige muito mais do professor do que a apresentação do "ponto" seguida de questionário ou de resolução de exercícios. Isso implica, necessariamente, em todos os casos, uma melhor formação pedagógica do professor e melhores condições de trabalho. 


\section{Referências}

BABBIE, E. Métodos de pesquisas de survey. Belo Horizonte: Ed. UFMG, 1999.

CARVALHO, A. M. P.; GIL-PÉREZ, D. Formação de professores de ciências: tendências e inovações. 2. ed. São Paulo: Cortez, 1995. (Questões de nossa época, 26).

FIORENTINI, D.; NACARATO, A. M. (Org.). Cultura, formação e desenvolvimento profissional de professores que ensinam matemática: investigando e teorizando a partir da prática. São Paulo: Musa; Campinas: Unicamp, 2005.

FRANCO, M. L. P. B. Análise do conteúdo. Brasília: Plano, 2003.

GARCÍA, C. M. Formação de professores: para uma mudança educativa. Porto: Porto Editora, 1999.

GARCÍA, J. E.; PORLÁN, R. Ensino de ciências e prática docente: uma teoria do conhecimento profissional. In: HARRES, J. B. S. (Org.). Ensino de ciências: teoria e prática docente. Lajeado: Univates, 2000. p. 15-23.

GOODSON, I. E. A construção social do currículo. Lisboa: Educa, 1997.

IMBERNÓN, F. Formação docente e profissional: formar-se para mudança e a incerteza. São Paulo: Cortez, 2004.

JAWORSKI, B.; GELLERT, U. Educating new mathematics teachers: integrating theory and practice, and the roles of practising teachers. In: BISHOP, A. J. et al. Second international handbook of mathematics education. Dordrecht: Kluwer, 2003. p. 829-875.

PÉREZ-GÓMEZ, A. O pensamento prático do professor: a formação do profissional reflexivo. In: NÓVOA, A. (Org). Os professores e sua formação. Lisboa: Dom Quixote, 1997. p. 93-114.

PINSONNEAULT, A.; KRAEMER, K. L. Survey research in management information systems: an assessment. Journal of Management Information Systems, Armonk, v. 10, n. 2, p. 75-106, 1993.

PIRES, C. M. C. Novos desafios para os cursos de licenciatura em matemática. Educação Matemática em Revista, São Paulo, v. 7, n. 8, p. 10-15, jun. 2000.

POLETTINI, A. F. F. Análise das experiências vividas determinando o desenvolvimento profissional do professor de matemática. In: BICUDO, M. A. V. (Org.). Pesquisa em educação matemática: concepções e perspectivas. São Paulo: Editora UNESP, 1999. p. 247-259.

ROLDÃO M. C. Formar para a excelência profissional - pressupostos e rupturas nos níveis iniciais da docência. Educação \& Linguagem, São Paulo, v. 10, n. 15, p. 18-42, jan-jun. 2007. Disponível em: $<$ https://www.metodista.br/revistas/revistas-ims/index.php/EL/article/view/155/165>. Acesso em: 30 out. 2011.

SCHÖN. D. A. Formar professores como profissionais reflexivos. In: NÓVOA, A. (Org). Os professores e sua formação. Lisboa: Dom Quixote, 1992. p. 77-92.

SHULMAN, L. S. Knowledge and teaching: foundations of the new reform. Harvard Educational Review, Cambridge, US, v. 57, n. 1, p. 1-22, 1987. 
STEPHENS, M. Regulating the entry of teachers of mathematics into the profession: challenges, new models, and glimpses into the future. In: BISHOP, A. J. et al. Second international handbook of mathematics education. Dordrecht: Kluwer, 2003. p.767- 793.

TARDIF, M. Saberes profissionais dos professores e conhecimentos universitários: elementos para uma epistemologia da prática profissional dos professores e suas consequências em relação à formação para o magistério. Revista Brasileira de Educação, Rio de Janeiro, n. 13, p. 5-24, 2000. Disponível em: <http://educa.fcc.org.br/scielo.php?pid=S1413-24782000000100002\&script=sci_abstract >. Acesso em: 30 out. 2011.

Saberes docentes e formação profissional. 10. ed. Petrópolis: Vozes, 2010.

TARDIF, M.; LESSARD, C.; LAHAYE, L. Os professores face ao saber: esboço de uma problemática do saber docente. Teoria \& Educação, Porto Alegre, n. 4, p. 215-234, 1991.

THOMPSON, A. G. The relationship of teachers' conceptions of mathematics and mathematics teaching to instructional practice. Educational Studies in Mathematics, New York, v. 15, n. 2 , p. 105-127, 1984.

ZABALA, A. A prática educativa: como ensinar. Porto Alegre: Artmed, 1998.

ZEICHNER, K. M. Formação reflexiva de professores: idéias e práticas. Lisboa: Educa, 1993. 